\title{
A CIDADANÍA E 0 DESAFÍO ECOLÓXICO
}

\author{
Andrew Dobson \\ Universidade de Keele (Reino Unido)
}



O concepto de cidadanía ocupa un espazo discursivo moi debatido, aínda que xa establecido, dentro da política moderna e existen catro puntos de referencia aceptados en liñas xerais. En primeiro lugar, a cidadanía interpreta as relacións políticas... unhas veces entre os membros dunha organización política e outras entre os tales membros e a organización en si. En segundo lugar, o acento que se pon nas relacións políticas é importante porque para que o concepto de cidadanía siga a ter algún significado tras o seu encontro coa ecoloxía política cómprenos ser quen de diferenciala doutros tipos de relacións, tales coma as establecidas coa amizade ou a familia. En terceiro lugar, a organización política asociada con maior frecuencia á cidadanía contemporánea é o Estado-nación. E, en cuarto lugar, adóitase falar das relacións en cuestión en termos de dereitos e responsabilidades.

Xa que logo, polo que á cidadanía respecta, o «desafío ecolóxico» poderíase referir a calquera destes elementos que constitúen a arquitectura da cidadanía: quen ou que poden ser os seus membros, que é o que conta como "político", cal é a natureza do espazo en que se desenvolven as relacións da cidadanía e que clases de dereitos e responsabilidades pode levar implícitos a cidadanía.

\section{A CIDADANÍA: CONTEXTO}

Estamos afeitos a pensar que hai, como mínimo, dous tipos diferentes de cidadanía: o liberalismo e o republicanismo cívico. Diferéncianse fundamentalmente no seu concepto da natureza e do equilibrio existente entre os dereitos e as responsabilidades dos cidadáns. A tradición republicana cívica antepón a responsabilidade -tendo en conta o benestar da comunidade política- aos dereitos do individuo. Pola contra, a cidadanía que asociamos coa democracia liberal ten moito máis que ver coa esixencia de dereitos que co exercicio de responsabilidades. 
Na teoría republicana, a idea da contribución que o individuo pode facer á comunidade deu lugar a unha linguaxe de virtudes propias da cidadanía. Tradicionalmente, estas virtudes concibíronse en termos «masculinos»-afouteza, firmeza, sacrificio-, aínda que resulta que se entenden mellor como interpretacións masculinas do que estas virtudes poderían supoñer. A cidadanía liberal non carece de virtudes, por suposto (acotío faise referencia neste contexto ás virtudes da tolerancia e da ausencia de prexuízos), pero esta cidadanía non vai pregoando as súas virtudes do mesmo xeito ca os seus parentes republicanos.

Así pois, a cidadanía liberal e a republicana disputaron desde sempre polo significado e o equilibro dos dereitos e responsabilidades dos cidadáns, e polo papel que desempeña a virtude no comportamento político dos cidadáns.

Con todo, estes desacordos refírense a un único punto dos catro que antes mencionei e que constitúen a arquitectura da cidadanía: o dos dereitos e responsabilidades. Sobre os outros tres elementos, tanto republicanos coma demócratas concordan en liñas xerais.

Daquela, ambos concordan en que a esfera política está constituída por espazos públicos máis ca por privados, concordan en que o Estado-nación é o modelo básico de "receptáculo» para a cidadanía e concordan en que a pertenza á comunidade de cidadáns está relacionada coa pertenza ao Estado-nación.

Visto así, podemos considerar os desacordos, aparentemente fundamentais, entre liberais e republicanos como o que de verdade son: un pacto conveniente para ambos. A cidadanía ecolóxica, como idea, pono de manifesto moi claramente, como vou demostrar máis adiante.

Isto non quere dicir que non se expuxesen inconvenientes dun carácter máis fundamental. Por exemplo, as críticas feministas á cidadanía puxeron de relevo como a representación supostamente universal da cidadanía - presente tanto no bando republicano como, sobre todo, no liberal-é, no fondo, unha criatura sexuada cunhas características descritivas e unhas aspiracións que a converten quer en algo inapropiado para moitas mulleres, quer nun auténtico inimigo dos seus intereses.

Un elemento clave desta crítica é que pon en cuestión a exclusión da esfera privada da práctica e o discurso da cidadanía. Para a crítica feminista desta cidadanía masculina, o ámbito privado é tan lugar para a actividade da cidadanía como o ámbito público, e as virtudes da vida desenvolvidas propiamente na esfera pri- 
vada deberíanse considerar, a simple vista, virtudes políticas potenciais. Ao poñer en dúbida a estendida opinión acerca dun dos elementos que constitúen a arquitectura da cidadanía, e sobre o que, de feito, concordan os dous principais contendentes, a cidadanía feminista constitúe unha refutación fundamental dos modelos aceptados de cidadanía.

O cosmopolitismo presenta outra refutación esencial, que neste caso se refire á cuestión do «receptáculo» da cidadanía e ao acordo adoptado entre republicanos e liberais que propugna que a cidadanía só ten sentido como status xurídico e como actividade dentro dun Estado-nación, ou naqueles marcos inspirados no Estado-nación, como pode ser a Unión Europea.

A cidadanía cosmopolita céntrase nas reivindicacións políticas que se nos demandan como membros dunha humanidade común, e, así, o espazo político do cosmopolitismo -en contraste coa cidadanía liberal ou a republicana- é, en principio, a cosmópole universal máis ca un Estado-nación ou outro. Ao cuestionar un principio acordado tanto pola cidadanía liberal como pola republicana, o cosmopolitismo, do mesmo xeito que o feminismo, presenta un atranco considerable ás opinións comunmente aceptadas sobre a configuración da cidadanía.

\section{O DESAFÍO ECOLÓXICO PARA A CIDADANÍA}

Unha cuestión fundamental para os ecoloxistas políticos é saber se a ecoloxía política se pode falar na lingua da cidadanía. A contestación a esta pregunta non é nada obvia. As críticas feministas á resolución republicana e liberal de reservar a cidadanía para a esfera pública levaron a algúns a afirmar que a «cidadanía feminista» constitúe unha contradición en si mesma, porque a cidadanía é por definición un fenómeno propio do espazo político público.

Igualmente, sexa o que sexa o cosmopolitismo, para algúns dos seus críticos non é, de certo, unha teoría da cidadanía, porque esta só cobra sentido, por definición, no contexto do Estado-nación, ou de formacións políticas análogas. Nos dous casos, e segundo os seus críticos, tanto o feminismo como o cosmopolitismo fracasaron á hora de enfrontárense ao reto que lles lanza a cidadanía: non falan na súa lingua. Pero que ocorre co desafío ecolóxico? 
Sucumbirá aos mesmos problemas de definición que a cidadanía feminista ou a cosmopolita?

Pois ben, é posible que si porque, na miña opinión, o enfoque ecolóxico-político da teoría da cidadanía está construído sobre percepcións cosmopolitas e feministas. En concreto, toma en serio a idea de que a cidadanía pode e debe vincularse ao ámbito privado e que talvez sexa conveniente reconsiderar as virtudes asociadas á cidadanía de acordo cos parámetros normalmente asociados ao feminismo.

Ademais, a cidadanía ecolóxica coincide co cosmopolitismo na súa determinación por cuestionar se os Estados-nación -e os seus equivalentes- son unha expresión exhaustiva do espazo político da cidadanía. Neste contexto, a cidadanía ecolóxica quizais ofreza unha nova interpretación do espazo político da cidadanía coa súa "pegada ecolóxica», do cal falarei máis adiante.

\section{A CIDADANÍA ECOLÓXICA E O ÁMBITO PRIVADO}

Comentei xa que o cidadán ecolóxico, do mesmo xeito que acontece co seu homólogo republicano cívico, se ve animado a traballar polo ben común. No caso ecolóxico, este ben común denomínase «sustentabilidade ambiental». Este obxectivo implica, inevitablemente, determinar as causas e as fontes da non sustentabilidade ambiental e tentar facer algo por resolvelas.

Algunhas destas causas e fontes estarán fóra do alcance inmediato dos cidadáns concretos e, de todos os xeitos, moitas das posibles causas da falta de sustentabilidade son controvertidas. Está o medio natural baixo presión debido ao crecemento da poboación? É a pobreza unha das causas da non sustentabilidade? Ou a riqueza? É a culpable a nosa actitude para coa natureza? Ou será a combinación de todos estes factores ou doutros completamente distintos?

Este debate ten lugar na esfera pública, e na medida en que os nosos efectos sobre o medio se transmiten por e a través das nosas formas de vida social, a "cuestión da sustentabilidade» convértese nunha cuestión pública. Logo, resulta correcto e adecuado pensar na cidadanía ecolóxica en termos "públicos» tradicionais: argumentos e actividades que poderían influír en institucións, empresas, movementos, partidos, burocracias, escolas e ministerios para que actúen de maneira sustentable. 
No entanto, a política ecolóxica é tamén unha política cotiá, unha política que adopta e implica unha relación metabólica diaria entre os individuos e a natureza, ademais dunha relación mediada pola nosa presenza e participación nas instancias "públicas». E non podemos acender e apagar esa relación cando franqueamos unha presunta división existente entre o público e o privado.

Cunha expresión tomada do posmodernismo, diremos que nós somos «sempre xa» consumidores de servizos ambientais e produtores de residuos desde o momento en que nacemos ata o da nosa morte, no público e no privado, na saúde e na enfermidade. Desde este punto de vista, resulta retorcido considerar que facer campaña a favor dun centro de reciclaxe é un acto de cidadanía asemade que se lle nega esa consideración ao acto de separar os materiais biodegradables do resto só porque iso se fai na privacidade da casa de cada quen. O desafío ecolóxico consiste en considerar ambos os casos como actos de cidadanía.

As críticas feministas e ecolóxicas da concepción tradicional de cidadanía poden facer causa común nun segundo punto, relacionado este coa idea da virtude. É habitual comparar aquelas virtudes propias do republicanismo cívico -valor, firmeza, sacrificio- con aqueloutras preconizadas no contexto ecolóxico: coidado, agarimo, compaixón. O feminismo (ou algunhas das súas vertentes) tense asociado con estas últimas virtudes, sobre todo dentro do debate sobre xustiza fronte a coidado.

Pero, en realidade, pódense considerar estas como virtudes da cidadanía? Ao comezo deixei claro que, tras o seu encontro coa ecoloxía política, haberá que interpretar a cidadanía como se remitísemos a unha relación diferente daquelas que nos atopamos noutras áreas da vida, como a amizade ou a familia. Se adoptamos o coidado e a compaixón como virtudes da cidadanía, non correremos o risco de confundir a cidadanía coas relacións en que se supón que estas virtudes están máis presentes? Algúns pensan que si. Por exemplo, Michael Ignatieff escribiu: «A trapalleira retirada desde a linguaxe da xustiza cara á linguaxe do coidado é, se cadra, o signo máis preocupante da decadencia da linguaxe da cidadanía por parte de todos os partidos que se sitúan á esquerda da Sra. Thatcher» (Rees, 1995: 321) e conclúe afirmando que «a linguaxe da cidadanía non fala en sentido estrito de compaixón» (1991: 34). Por que non? 


\section{O PROBLEMA DA DEFINICIÓN}

A estas alturas debeu quedar claro que o concepto de cidadanía está fortemente custodiado polo que eu vou chamar Secretariado da Definición (SD). O ámbito privado queda fóra do concepto de cidadanía porque esta é, por definición, unha condición xurídica e unha actividade asociada coa esfera pública. Do mesmo xeito, a cidadanía cosmopolita é unha contradición en si mesma porque aquela, por definición, implica dereitos e deberes dentro dun Estado-nación, ou os seus equivalentes. E seica, segundo Ignatieff, o coidado e a compaixón, por definición, non son virtudes da cidadanía.

Mais coido que debemos andar con tento co SD. Unha cousa é afirmar que os conceptos políticos ocupan un territorio discursivo e outra ben diferente reducir ese territorio a un pequeno despacho onde se atopen os escritorios e arquivadores do SD. Hai polo menos tres razóns para pensar que os conceptos políticos se asemellan máis a seres vivos que respiran ca a insectos conservados en ámbar.

En primeiro lugar, son conceptos históricos. Desde este punto de vista, sería ben raro que a cidadanía significase o mesmo hoxe en día ca na antiga Grecia. Tomemos un exemplo do que hei falar con máis detalle: o «receptáculo» en que se di que a cidadanía adquire sentido. Na vida política contemporánea en realidade só existe un único candidato para ser ese «receptáculo»: o Estado-nación. Pero se lle botamos unha ollada á historia, observaremos unha ampla gama de alternativas: a antiga cidade-estado, o municipio, as primeiras cidades da república moderna. Non cabe dúbida de que no futuro os teóricos estudarán o desenvolvemento da Unión Europea e os nacentes dereitos transnacionais - tales como o dereito a votar nas eleccións locais «estranxeiras»-inherentes ao feito de ser cidadán dun dos países membros e argumentarán que este é un exemplo máis de cidadanía en acción en marcos diferentes aos do Estado-nación.

En segundo lugar, debemos pensar na cidadanía como unha actividade ademais de como un status xurídico. Se pensamos na cidadanía como unha actividade orientada a conseguir o ben común - un aspecto da experiencia histórica de cidadanía tan venerable como calquera outro-, daquela a cidadanía cosmopolita e a ecolóxica volven ser formas de cidadanía.

Para rematar, ademais de seren históricos e maleables desde dentro, os con-

ceptos políticos son iso, políticos. Con isto quero dicir que as definicións non 
poden quedar á marxe das relacións do poder político que pretenden describir. Mantéñense nunha relación complexa con este poder: nin o reflicten simplemente nin o cuestionan sen máis. Neste aspecto, a cidadanía é un espazo de loita política, e os desafíos que lle lanzan a ecoloxía, o cosmopolitismo e o feminismo equivalen ao reto de incorporarlle estas novas políticas. Se o persoal é político, pode a cidadanía darlle as costas á esfera do privado? Nun mundo globalizado, non ten absolutamente nada que dicir a cidadanía sobre as obrigas transnacionais? Ten que permanecer en silencio sobre a sustentabilidade ambiental nos seus contextos «infraestatais» e "extraestatais» só porque o status de cidadanía comeza e remata no Estado-nación ou nos seus equivalentes?

\section{A CIDADANÍA ECOLÓXICA E A PEGADA ECOLÓXICA}

Permítanme abordar este último tema. Un aspecto obvio dos problemas ambientais é que non respectan as fronteiras. Neste contexto adoitamos pensar en problemas ambientais de carácter transnacional, coma o quecemento global ou a redución da capa de ozono. $\mathrm{Na}$ medida en que estes problemas teñen unha dimensión política, parece perverso rexeitar calquera crítica que se lle faga desde un concepto tan fundamentalmente político coma o da cidadanía polo simple feito de que a cidadanía é (dise que é) unha creación do Estado-nación contemporáneo.

Desde os estoicos, o cosmopolitismo ofreceulles un imaxinario alternativo para o espazo político aos receptáculos delimitados, coma as municipalidades, as cidades ou os estados. A primeira vista, parece unha fonte ideal de inspiración para un fenómeno de características transnacionais como é a ecoloxía política. A cosmópole mundial dos cosmopolitas e o escenario de ámbito planetario da ecoloxía política parecen ser proveitosamente coincidentes.

No entanto, non se deberían trasladar de modo simplista as concepcións cosmopolitas á nosa interpretación da cidadanía ecolóxica. Por unha banda, as obrigas cosmopolitas sobre os individuos emanan da pertenza a unha «humanidade común». A linguaxe da simetría, a reciprocidade e a interdependencia son algo esencial para o cosmopolitismo, pero algunhas interpretacións dos impulsores deste movemento e a dinámica dos problemas ambientais parecen indicar que 
estes problemas se orixinan e se experimentan de forma asimétrica (os pobres adoitan vivir en ambientes pobres e os ricos en ambientes ricos) e que isto tamén se debería ver reflectido na natureza e na orientación das obrigas da cidadanía.

Sendo así, se non se trata da cosmópole, cal é a natureza do espazo político no que teñen lugar as relacións dos cidadáns ecolóxicos? Coido que aquí nos cómpre introducir o concepto de "pegada ecolóxica».

Esta idea desenvolveuse para ilustrar os diversos impactos que teñen sobre o medio as prácticas sociais de individuos e comunidades. Suponse que a Terra ten unha capacidade produtiva e de absorción de residuos limitada e, en vista destes límites, asígnaselle a cada habitante do planeta unha hipotética e igual «parcela de terra»-ou pegada. O tamaño desta pegada obtense dividindo o total de terras e a súa capacidade produtiva dispoñible polo número de persoas que habitan o planeta, e a cifra resultante está entre 1,5 e 1,7 hectáreas. Inevitablemente, algunhas persoas terán un maior impacto - unha pegada meirande- ca outras (crese que os consumidores medios dos "países industriais avanzados» ocupan, polo xeral, unhas cinco hectáreas de espazo ecolóxico) e isto é inxusto, se partimos dunha igualdade nominal de espazo ecolóxico.

Para nós, a importancia da pegada ecolóxica é que contén as relacións clave espaciais e xeradoras de obrigacións que dan lugar ao exercicio de virtudes especificamente cidadás. A miña cidadanía ecolóxica «créase», por así dicilo, porque teño unha pegada ecolóxica. E todos temos unha, conque todos somos cidadáns ecolóxicos. Todos temos dereito a unha cantidade habitable de espazo ecolóxico e todos temos a obriga de diminuír o tamaño do devandito espazo se é demasiado grande, é dicir, se excede a cantidade que, hipoteticamente, nos corresponde no repartimento.

Así pois, a natureza da nosa obrigación como cidadáns ecolóxicos é reducir a ocupación do espazo ecolóxico onde corresponda. E a fonte desta obrigación radica en remediar a inxustiza real e potencial de apropiarse dunha cota inxusta do devandito espazo.

E o que é importante, isto explica e reflicte a natureza asimétrica e non recíproca das obrigas da cidadanía ecolóxica. Este é o motivo polo que non se pode trasladar de xeito simplista o cosmopolitismo á nosa noción de cidadanía ecolóxica. As obrigas cosmopolitas baséanse na nosa suposta pertenza a unha humanidade común e son, xa que logo, recíprocas e simétricas. As obrigas da 
cidadanía ecolóxica fundaméntanse na asimetría, é dicir, na ocupación desigual do espazo ecolóxico. Sendo así, estas obrigas correspóndenlles exclusivamente a aqueles que contraeron unha débeda ecolóxica con respecto ao espazo, e constitúen o corolario dun dereito ambiental a un repartimento igualitario do espazo ecolóxico entre todos.

En resumo, cada proxecto político contén, quer implícita, quer explicitamente, unha interpretación do espazo político, e a procura da sustentabilidade ambiental non é ningunha excepción. Aquí, coido eu, é onde reside o desafío ecolóxico máis significativo para o concepto de cidadanía. Ademais do Estado, do supra-estado ou da comunidade dialóxica da cidadanía cosmopolita, o ambientalismo ofrece a pegada terrea como imaxinario espacial no que mellor se conciben a cidadanía e as súas obrigas.

\section{CRÍTICAS Á CIDADANÍA ECOLÓXICA}

Téñense feito diversas críticas á cidadanía ecolóxica, e estou disposto a aceptar algunhas delas, pero hai unha ou dúas ás que me inclino máis a opoñerme. Estas críticas pódense agrupar baixo os seguintes encabezados: o problema da pertenza á comunidade do cidadán ecolóxico; demasiada énfase nos individuos e non abonda na estrutura; en sentido estrito, a cidadanía ecolóxica non é en absoluto unha forma de cidadanía; a pegada ecolóxica non se pode considerar como un espazo "político», e moito menos como un espazo onde poida operar a cidadanía; e, por último, a crítica feminista de que a cidadanía ecolóxica, coa súa insistencia en que as accións privadas poden ter importantes consecuencias públicas, impón unha carga inxusta de responsabilidade a aquelas que xa soportan unha responsabilidade demasiado grande na reprodución da vida social.

No que atinxe á comunidade do cidadán ecolóxico, Tim Hayward escribiu que «Os lazos da cidadanía [ecolóxica] obrigan nunha única dirección, a dos beneficiarios das desigualdades; aos outros atribúeselles en realidade o papel de "pacientes morais". Esta explicación non establece con claridade se algunha comunidade política inclúe as vítimas como cidadáns. Unha cuestión fundamental é se as vítimas -p. ex., os que máis perden coa privación ecolóxica e as obrigas derivadas dela- poden ser ou non cidadáns ecolóxicos» (2006a: 445). 
Os teóricos da cidadanía están preocupados con razón pola cuestión da pertenza; despois de todo, decidir quen é ou non membro dunha comunidade cidadá dada determina quen goza dos dereitos (e obrigas) inherentes á cidadanía. No entanto, esta preocupación pola pertenza está confinada maiormente aos debates sobre a cidadanía como status xurídico -o tipo de cidadanía asociada á posesión dun pasaporte. A cidadanía ecolóxica está menos relacionada co status xurídico e máis coa cidadanía como actividade. Desde este punto de vista, a pertenza non é realmente un problema.

Unha vez dito isto, non obstante, e para contestar directamente á cuestión de Hayward, as "vítimas» do comportamento non sustentable si poden ser cidadáns ecolóxicos. E isto é así porque o seu dereito a unha cantidade xusta de espazo ecolóxico impón a aqueles que ocupan demasiado espazo ecolóxico a obriga de reduciren o tamaño da súa pegada ecolóxica. «Vítimas» e «actores» están xuntos nunha cidadanía que chanta os seus alicerces nas relacións entre obrigas e dereitos políticos.

A seguinte crítica que foi lanzada contra a cidadanía ecolóxica é que é demasiado "voluntarista», que contén unha visión naif das capacidades dos individuos para dar lugar ao cambio social. O seu argumento é que as teorías do cambio deben ter en conta as estruturas en que actúan os axentes individuais, estruturas que fan difícil que os individuos reduzan o tamaño da súa pegada ecolóxica.

Coido que é xusto dicir que esta cuestión está, en realidade, infrateorizada no meu libro Citizenship and the Environment, aínda que si digo nel que é importante evitar «o voluntarismo inxenuo e ignorante dos poderosos intereses políticos e económicos que estruturan o mundo dun modo non sustentable». Poderíase e deberíase engadir moito máis a isto, e a cidadanía ecolóxica como actividade intencional individual deberíase incluír nunha análise das estruturas que teña en conta as restricións (e quizais, por suposto, as oportunidades) culturais, organizativas e infraestruturais dos axentes individuais. $\mathrm{O}$ resultado podería ser o de poñer unha maior énfase no papel do cidadán ecolóxico en actividades de cidadanía "tradicional» na sociedade civil e na esfera pública -axitación, campañas, protestas- así como nas actividades que a miúdo se categorizan pexorativamente coa expresión «estilo de vida».

A seguinte crítica é que, respecto dunha definición formal, a cidadanía ecolóxica non é cidadanía en absoluto. Tim Hayward resume esta crítica como 
segue: «Normalmente, a idea de cidadanía refírese, inter alia, a un status que xorde coa pertenza a un estado e que lles confire aos cidadáns un conxunto de responsabilidades e dereitos recíprocos [...]. Nunha interpretación convencional, polo tanto, o que Dobson chama "cidadanía" non contaría como tal» (2006a: 435).

Desde o punto de vista da cidadanía como un status xurídico en relación con un estado que confire a cidadanía, Hayward está totalmente no certo. Por suposto, tal punto de vista obrigaría tamén a Hayward a rexeitar que a cidadanía cosmopolita sexa cidadanía porque non hai unha «organización política» nin criterios de «pertenza» mundiais. A pesar diso, a presenza lexítima da cidadanía cosmopolita na literatura sobre o concepto de cidadanía parece absolutamente firme. Unha vez máis cómpre distinguirmos entre cidadanía como status xurídico e como actividade. Se estamos dispostos a aceptar que a cidadanía pode ser considerada como unha actividade, daquela os criterios definitorios estipulados por Hayward resultan menos relevantes para o noso caso.

A seguinte crítica é tamén de definición. A "pegada ecolóxica» xoga un papel clave na miña exposición sobre a cidadanía ecolóxica. Todas as concepcións da cidadanía conteñen unha versión do "espazo político» da cidadanía. De modo xeral, o espazo político das concepcións dominantes de cidadanía é o Estado-nación, namentres que para a cidadanía cosmopolita é a "cosmópole», ou o mundo no seu conxunto. Para a cidadanía ecolóxica, o espazo significativo é a pegada ecolóxica.

Tim Hayward oponse a isto, baseándose en que «as relacións definidas en termos de utilización diferencial do espazo ecolóxico son, precisamente, relacións non políticas» (2006a: 438). É así porque, como di: «a idea de que o espazo ecolóxico é "a versión que dá a cidadanía ecolóxica do espazo político" supón un erro categorial: porque namentres que ningún tipo de "espazo" traza parcelas diferenciadas de territorio, o primeiro refírese non obstante ás características biofísicas do territorio, non ao "espazo" dentro do cal a xente ten relacións políticas» (2006a: 438).

A miña resposta é que as pegadas ecolóxicas desiguais son unha inxustiza, que a (in)xustiza é un concepto político porque supón relacións de poder e que, daquela, a pegada ecolóxica, como unha área en que se exerce poder, é un espazo político. 
Por último, debemos ter en conta a crítica feminista que di que a cidadanía ecolóxica, ao poñer o acento na esfera privada, impón unha carga inxusta sobre a muller. As feministas teñen aducido a miúdo que a muller adoita desempeñar un dobre papel -traballando no mercado laboral e ocupándose da provisión e coidado da casa. Por esta razón, feministas coma Sherilyn MacGregor invítannos a reflexionar sobre "as consecuencias para a muller de engadir un terceiro ou cuarto papel -o de "coidar da Terra"- a unhas vidas xa tan ocupadas de por si» (2005: 185).

Esta é, de certo, unha cuestión ben importante. Foi de sempre un receo feminista que o proclamado universalismo da cidadanía sexa, no fondo, unha forma machista de política que favorece os intereses do home (Young, 1989). MacGregor recolle as repercusións prácticas disto e mostra como, para que a cidadanía ecolóxica teña forza emancipadora, debe ter en conta as circunstancias materiais dos que se espera que sexan cidadáns e cidadás ecolóxicos: "Coido que para que calquera proxecto dunha sociedade alternativa funcione e melloren as actuais circunstancias, debe facer fronte a cuestións de equidade, de acceso, e ás condicións da vida diaria necesarias para promover a participación democrática no ámbito político» (2005: 185). Isto é importante para todos, pero especialmente, como sinala MacGregor, para as mulleres.

Velaquí algunhas das críticas que se lle fixeron ao concepto de cidadanía ecolóxica, e algunhas das miñas respostas. É evidente que se trata dun concepto en evolución máis ca dun totalmente formado. Tampouco sabemos como había funcionar esta idea na práctica, é dicir, se conseguiría influír na conduta e nas actitudes da xente para que o seu comportamento fose máis ecolóxico.

Mais iso daría lugar a outra conferencia. 


\section{BIBLIOGRAFÍA}

Berglund, C. e S. MATti: "Citizen and consumer: the dual role of individuals in environmental policy», Environmental Politics, 15/4 (2006), p. 550-571.

Dobson, A.: "Citizenship», en A. Dobson e R. Eckersley (eds.), Political Theory and the Ecological Challenge, Cambridge, Cambridge University Press, 2006.

FlynN, F., B. Bellaby e M. Ricci: «Environmental citizenship and public attitudes to hydrogen energy technologies», Environmental Politics, 17/5 (2008), p. 766-783.

Gabrielson, T.: "Green citizenship: a review and critique», Citizenship Studies, 12/4 (2008), p. $429-446$.

HaYWARD, T.: «Ecological Citizenship: Justice, Rights and the Virtue of Resourcefulness», Environmental Politics, 15/3 (2006a), p. 435-446.

HaYward, T.: «Ecological Citizenship: a Rejoinder», Environmental Politics, 15/3 (2006b), p. $452-453$.

IGNATIEFF, M.: "Citizenship and moral narcissism», en G. ANDrEWs (ed.), Citizenship, Londres, Lawrence and Wishart, 1991.

JAGERS, S.: «In search of the ecological citizen», Environmental Politics, 18/1 (2009), p. 18-36.

LATTA, P.: «Locating democratic politics in ecological citizenship", Environmental Politics, 16/3 (2007), p. 377-393.

Litman, T.: «London Congestion Pricing: Implications for Other Cities», Victoria Transport Policy Institut, Canada, 2004. http://www.vtpi.org/london.pdf

LUQUe, E.: «Researching Environmental Citizenship and its Publics», Environmental Politics, 14/2 (2005), p. 211-225.

MACGregor, S.: «The public, the private, the planet and the province: women's quality-of-life activism in urban southern Ontario", en M. Hessing, R. Raglan e C. Sandilands (eds.), This Elusive Land, Women and the Canadian Environment, Vancouver, University of British Columbia Press, 2005.

Melo-Escrinuela, C.: «Promoting Ecological Citizenship: Rights, Duties and Political Agency», Acme, 7/3 (2008), p. 113-134.

MidDlEMISS, L.: «Reframing Individual Responsibility for Sustainable Consumption: Lessons from Environmental Justice and Ecological Citizenship», Environmental Values, $19 / 2$ (2010), p. 147-167.

ReEs, A. M.: "The Promise of Social Citizenship», Policy and Politics, 23/4 (1995), p. 313-325.

Valencia, A: "Globalisation, Cosmopolitanism and Ecological Citizenship», Environmental Politics, 14/2 (2005), p. 163-178.

Valdivielso, J.: «Social Citizenship and the Environment», Environmental Politics, 14/2 (2005), p. 239-254 .

Wolf, J., K. BROWN e D. CONWAY: «Ecological citizenship and climate change: perceptions and practice», Environmental Politics, 18/4 (2009), p. 503-521.

YounG, I. M.: «Polity and Group Difference: A Critique of the Ideal of Universal Citizenship», Ethics, 99/2 (1989), p. 250-274. 